\title{
TRANSGRESIONES DE LA REALIDAD: APROXIMACIONES AL CUENTO DE TERROR CHILENO MODERNO (1950-1960)
}

\author{
TRANSGRESSIONS OF REALITY: APPROACHES TO THE MODERN \\ CHILEAN TERROR SHORT STORY (1950-1960)
}

\section{Jesús DIAMANTINO VALDÉS}

Universidad Adolfo Ibáñez (Chile)

\begin{abstract}
Resumen: En el presente artículo planteamos una reflexión teórica sobre la estética del terror en la ficción literaria. Expondremos una clasificación que se desglosa en tres categorías: la transgresión del cuerpo, la transgresión cronotópica y la transgresión de los parámetros sociales. Esta propuesta teórico-analítica, tiene como objetivo delimitar los mecanismos que articulan el terror ficcional para disociarlo de lo fantástico. Comprobaremos estos preceptos a través del examen de cinco relatos de tres autores chilenos representativos de la primera mitad del siglo XX: Francisco Coloane, Luis Alberto Heiremans y Braulio Arenas. Este periodo nos parece significativo ya que legitima el desarrollo de lo fantástico y el terror como vertientes autónomas en la narrativa chilena.
\end{abstract}

Palabras clave: Estética del terror; transgresión; terror fantástico; narrativa chilena.

\begin{abstract}
This article intends to address a theoretical reflection on terror aesthetics in literary fiction. A clasification will be presented considering three categories: body transgression, chronotopic transgression and social parameters transgression. This analytical-theoretical proposal aims to delimitate the mechanisms that embody the fictional terror so as to separate it from the fantastic genre. We will probe these precepts through the revision of three short stories from Chilean writers who lived during the first half of XXth century: Francisco Coloane, Luis Alberto Heiremans and Braulio Arenas. This period is relevant since it legitimates the development of the fantastic and the terror as autonomous lines in Chilean narrative.
\end{abstract}

Key words: Terror aesthetics; Transgression; fantastic terror; Chilean narrative. 


\section{1}

\section{El terror como forma estética y sus transgresiones ${ }^{1}$}

Una de las mayores complicaciones al abordar el terror como sustancia estética es la imposibilidad de bosquejar sus contornos. Lo terrorífico adquiere diversos matices dependiendo de su representación, ya sea como dispositivo o como efecto. En otras palabras, la forma terrorífica es en sí misma un recipiente de contenido: una forma ambigua enmascarada por clasificaciones convencionales (un vampiro, un fantasma, un hombre-lobo, etc.) pero que articula la experiencia discursiva de lo velado. De esta forma, el miedo emerge como una consecuencia perlocutiva; como la prolongación de la extrañeza hacia el plano extratextual. Es en este punto en donde lo fantástico se emparenta con el terror, en cuanto a que este último desgarra los contornos de lo que entendemos como armonioso. Según Carrera Garrido, «El terror nos pone ante un más allá, pero no de la existencia o el universo, sino del dique que nos separa de lo desagradable de este mundo y nosotros mismos: una parcela oscura y amenazante, contraria a la razón, la moral y el buen gusto, que sepultamos bajo tabúes y hacemos como si no existiera» (2015: 78).

Lo terrorífico opera desde el principio de la desproporción y la destrucción; como amenaza, esta forma ficcional viola la arquitectura racional y desdibuja la identidad del sujeto. Entonces, el terror se adhiere a lo fantástico como un germen que potencia en gran medida la fractura con el mundo real, pero no es un mecanismo indispensable para propiciar este quiebre. En este sentido, la gran diferencia entre el terror y lo fantástico, es que el primero se define como un componente discursivo y el segundo, como una vertiente genérica.

Ciertos rasgos de lo fantástico admiten la permeabilidad de lo terrorífico. Por ejemplo, la escenificación de un mundo coherente con la realidad del lector. Dicho plano de identificación servirá para establecer una conexión con las creencias empíricas y cognoscitivas del lector. Sumado a esto, lo fantástico supone una oposición entre dos planos significantes: uno amparado por la razón y el otro por una lógica incomprensible. Esta confrontación se produce a partir de la irrupción de lo sobrenatural como un desajuste en el marco lógico de la realidad representada. Sin embargo, lo fantástico también implica un desafío a los convencionalismos de la realidad extratextual del lector, la cual está sujeta a diversas modelaciones contextuales (sociales, científicas, políticas, etc.). En este sentido, el objetivo de lo fantástico, según el teórico David Roas, es «desestabilizar esos límites que nos dan seguridad, problematizar esas convicciones colectivas (...) cuestionar la validez de los sistemas de percepción de la realidad comúnmente admitidos» (2011:35).

A modo de ejemplo, la asociación del terror y lo fantástico se hace evidente en el desarrollo de gran parte de la narrativa no mimética europea y norteamericana. En primer lugar, en la época

\footnotetext{
${ }^{1}$ Algunas reflexiones de esta sección tienen su origen en el estudio titulado «Fronteras de la alteridad: lo fantástico y sus límites», realizado por el autor del presente artículo e incluido en el libro Rutas inciertas. Nuevos cuentos chilenos de terror, misterio y fantasía (2017: 15-25).
} 


\section{Tropelías. Revista de Teoría de la Literatura y Literatura Comparada, 32 (2019) \\ Transgresiones de la realidad: aproximaciones al cuento de terror chileno moderno (1950-1960)}

decimonónica predominan tres figuras terroríficas: el fantasma, el vampiro y el doppelgänger («Corazones perdidos» de M. R. James, «El vampiro» de John Willliam Polidori o «William Wilson» de Edgar Allan Poe), como símbolos de los cambios suscitados por la Revolución Industrial, el ascenso de la burguesía y el sentimiento de alienación ante la ciudad moderna occidental. Después, en las tres primeras décadas del siglo XX, lo sobrenatural emerge en lengua inglesa desde la revalorización del mito y lo arquetípico; lo fantástico explora dimensiones inabarcables y legitima la insignificancia del sujeto ante potestades infinitas y secretos ancestrales, los que metafóricamente dan cuenta de crisis pre-bélica y el desmoronamiento de los grandes discursos de la Modernidad («La llamada de Cthulhu» de H. P. Lovecraft). Posteriormente, tanto en la literatura como en el cine, el miedo empieza a materializarse en obras miméticas que rearticulan los móviles argumentales del gótico clásico y los de la novela policial finisecular. Esta corriente exploró perversas temáticas como el sadismo, la locura y la violencia sectaria, exaltando aquellas perversiones soterradas por el conservadurismo capitalista ( $L a$ maldición de los Dain de Dashiell Hammer o Psicosis de Robert Bloch). Esta bifurcación del terror podría fundamentarse en el hecho de que los miedos colectivos engendrados después de las guerras mundiales se focalizaron en la imagen concreta de un «otro» identificable en la realidad. De esta forma, podemos pensar en el terror como una forma de representación transversal.

La asimilación del terror como elemento estético comienza a perfilarse en Occidente desde la difusión de la Indagación filosófica sobre el origen de nuestras ideas acerca de lo sublime y lo bello (1757), de Edmund Burke y la publicación de la novela El castillo de Otranto (1765), de Horace Walpole, en donde el terror se legitima como una posibilidad de expresión artística reclamando un goce hasta entonces vetado por los postulados neoclásicos. Al respecto, Burke afirma que «no hay pasión que robe tan determinantemente a la mente todo su poder de actuar y razonar como el miedo. Pues el miedo, al ser una percepción del dolor o de la muerte, actúa de un modo que parece verdadero dolor. Por consiguiente, todo lo que es terrible en lo que respecta a la vista, también es sublime» (2010: 86). En este sentido, la exaltación romántica ${ }^{2}$ se convierte en la vía idónea para extrapolar los miedos e inquietudes del sujeto moderno, y la novela gótica ${ }^{3}$ será la primera manifestación de esta nueva

\footnotetext{
${ }^{2}$ A principios del siglo XIX, el romanticismo alemán dará lugar a historias emparentadas con las creencias populares y alejadas de la estética macabra propia del gótico. Estos relatos se caracterizan por construir ambientes maravillosos en un espacio cotidiano. Ludwin Tieck (1773-1853) y Adelbert von Chamisso (1781-1838) fueron los representantes más importantes de esta tendencia. La maravillosa historia de Peter Schlemihl (novela escrita por Chamisso en 1814) es estimada por algunos críticos como la mejor novela fantástica alemana. En esta historia se mezclan los elementos del cuento popular y de la tradición folclórica en un espacio de la vida diaria. Sin embargo, será E. T. A. Hoffmann quien sentará las bases del cuento fantástico en toda Europa. Sus relatos estarán sujetos a elementos perturbadores; visiones fantasmagóricas que terminarán por destruir poco a poco la tranquilidad de la vida burguesa. En sus cuentos se percibe un aire de ensueño que, al volverse progresivamente maligno, terminará por trastornar la mente de sus personajes. Un ejemplo claro es «El hombre de Arena»; cuento que evoca las creencias populares, los misterios de la alquimia y la deshumanización.

${ }^{3}$ El gótico literario fue un movimiento artístico que reaccionó contra el orden clásico, regular y equilibrado del siglo XVIII, una reacción de rechazo a la novela familiar de Samuel Richardson y Henry Fielding, y de reincorporación de elementos sentimentales y fantasiosos. Esta literatura ofrecía al lector, cansado del rigor clasicista y educativo, una nueva posibilidad de reencontrarse con la emotividad y lo sobrenatural. Es por ello que la novela gótica incorporó elementos estéticos medievales y renacentistas, tales como viejas mazmorras, ruinas corroídas y principalmente el castillo. Incorporó además, rasgos de la dramaturgia grecolatina. Sus ingredientes de superstición y tintes macabros quedan enmarcados dentro de su arquitectura laberíntica. El castillo gótico se convierte en el verdadero protagonista de estas historias, aportando todos los
} 
pulsión estética, siendo el semillero de múltiples elementos temáticos y argumentales que hasta el día de hoy tienen vigencia: el castillo embrujado (la casa encantada), la violencia sexual, los crímenes pasionales, los espectros vengativos, la brujería y lo profano, etc.

\section{H. P. Lovecraft (1890-1937), en su ensayo El horror sobrenatural en la literatura (Supernatural} horror in literature) (1937), señala que el miedo es el sentimiento primigenio del hombre. El miedo a lo «desconocido» sería el motor principal de los cuentos de terror; ese espanto inefable e incontrolable que acaba trastornando la razón hasta la demencia (Lovecraft, 2008: 1041). Por este motivo, el autor de Providence hace hincapié en la elaboración de la atmósfera en los relatos de «horror» más que en el encaje de una trama determinada, ya que el escritor debe, por norma general, crear una sensación que anule por completo una explicación racional frente a lo extraordinario, otorgándole un lugar privilegiado al elemento sobrenatural amenazador como un reflejo de la incertidumbre del sujeto.

Cercano al planteamiento de Lovecraft, el psicoanalista austriaco, Sigmund Freud, instalará en 1919 el término «siniestro» (Unheimliche) para designar la sensación de terror que generan las cosas familiares desde la niñez. Utilizando como objeto de estudio el clásico cuento «El hombre de arena», de E. T. A. Hoffmann, intenta dilucidar cómo una experiencia marginada en la infancia puede tornarse pavorosa en la adultez. En concreto, destaca la potencialidad ominosa de lo fantástico como puente para dilucidar los mecanismos del inconsciente; develando así los traumas y frustraciones del sujeto moderno, el cual irremediablemente se verá trastocado por las pulsiones siniestras que el poeta manifiesta en la luz de lo cotidiano, remitiendo al receptor a sus miedos reprimidos. Así, la hiperrealidad resulta esencial para denotar el terror:

\footnotetext{
Muy distinto es, en cambio, si el poeta aparenta situarse en el terreno de la realidad común. Adopta entonces todas las condiciones que en la vida real rigen la aparición de lo siniestro, y cuanto en las vivencias tenga este carácter también lo tendrá en la ficción [...] nos libra entonces de nuestra superstición, que habíamos creído superada; nos engaña al prometernos la realidad vulgar, para salirse luego de ella. Reaccionamos ante sus ficciones como lo haríamos frente a nuestras propias vivencias; una vez que nos damos cuenta de la mixtificación, ya es demasiado tarde, pues el poeta ha logrado su objetivo (Freud, 2013: 2504).
}

De la cita anterior, podemos deducir que la desfiguración de la realidad propicia lo siniestro. En otras palabras, la forma terrorífica se articula a partir de la ambigüedad que suscitan la imbricación de lo cotidiano y lo oculto. En concreto: lo siniestro aflora en la medida en que la experiencia reprimida emerge cuando la realidad se hace imprecisa e incierta, tanto para los personajes como para los lectores. En la escuela romántica, por ejemplo, «la técnica narrativa y la estructura metafórica pueden llevar al lector a conclusiones ambiguas y paradójicas, el mundo de lo siniestro en el texto comienza por llevar al lector más allá de la mera identificación con los personajes» (Mancilla, 2017: 57).

Como señalamos anteriormente, el miedo es uno de los componentes más comunes y característicos de lo fantástico. Dicho efecto tiene lugar en el momento en que queda en evidencia la permeabilidad de lo extraño en el plano de la lógica, pues el quiebre de la realidad implica el

elementos que pudieran seducir al lector: pasadizos subterráneos, viejas galerías, puertas batientes. También la naturaleza se torna pintoresca: hiedra tupida, oscuros bosques, tormentas, noches de luna, etc. 


\section{Tropelías. Revista de Teoría de la Literatura y Literatura Comparada, 32 (2019) \\ Transgresiones de la realidad: aproximaciones al cuento de terror chileno moderno (1950-1960)}

21

desmoronamiento de aquello que nos tranquiliza y nos legitima como seres racionales. En otras palabras, el terror en el ámbito artístico implica la materialización, presencia o sugerencia de una amenaza.

Por supuesto, hay miedos que devienen de la naturaleza misma del ser humano, como aquellos que advierten sobre los peligros o amenazas y que propician el afán de supervivencia u otros más vanos que se relacionan con la preservación de los bienes materiales, el estatus social o la pérdida de la juventud. Sin embargo, el género del terror se nutre de un pavor todavía más complejo, aquel que el filósofo Zygmunt Bauman denominó «miedo derivativo», entendido como el «sedimento de una experiencia pasada de confrontación directa con la amenaza: un sedimento que sobrevive a aquel encuentro y que se convierte en un factor importante de conformación de la conducta humana aun cuando ya no exista amenaza directa alguna para la vida o la integridad de la persona» (2015: 11). En otras palabras, el miedo podría definirse como una sustancia traumática que vive solapada al interior del sujeto y que pervive más allá de las capas racionales; concepto que articula un oscuro puente entre la realidad y lo subjetivo.

Lo anterior se depura a través de dos grandes subcategorías para el abordaje de lo macabro: el «terror sustancial», el cual se refiere a aquellas ficciones en donde el miedo se enmarca y focaliza en una dimensión reconocible, tanto para los personajes como para los receptores; en el que, si bien pudiese presentarse una tensión fantástica, esta se disipa gradualmente cuando asimilamos la amenaza como algo reconocible en la realidad. Persiste de todas formas una perturbación gracias a la hiperbolización de la violencia o el quiebre abrupto con los parámetros conductuales; por ejemplo, las ficciones sobre asesinos seriales o las historias apocalípticas que involucran desastres biológicos o naturales (Soy leyenda (1954), de Richard Matheson), o la amenaza de la naturaleza y sus componentes (Cujo (1981), de Stephen King). Y el «terror sobrenatural», unidad que engloba a todas aquellas obras en donde el eje articulador es una amenaza extraña que carece de explicación lógica, desestabilizando de forma más evidente el universo cognoscible, siempre de manera destructiva y angustiosa; por ejemplo, Drácula (1897), de Bram Stoker o Vuelta de tuerca (1898) de Henry James. Desde esta lógica, el escritor Thomas Ligotti sentencia que la ficción de lo extraño (en otras palabras, el «terror fantástico») involucra «una sensación de lo que podría ser denominado irrealidad macabra: macabra por la presencia de algo amenazador y horrible, e irreal, por la imposibilidad de definir lógicamente aquella amenaza» (2016: 26).

El terror —independientemente de la clasificación recién propuesta — se despliega a través de tres categorías significativas: la transgresión del cuerpo, la transgresión cronotópica y la transgresión de los parámetros sociales. La primera de ellas incorpora obras que exploran las diversas formas de la monstruosidad, la degradación física, la metamorfosis, la deshumanización y la reencarnación. Estas ficciones proyectan la desproporción y el desequilibrio del sujeto, recayendo en él la connotación primitiva, la lujuria y el descontrol. En otras palabras, la transgresión del cuerpo encarna la dualidad y las pulsiones destructivas del hombre, las cuales afloran como un reflejo de los miedos ante el desarraigo de la armonía (Frankenstein de Mary Shelley o El extraño caso del doctor 
Jekyll y el señor Hyde de Robert Louis Stevenson). En este sentido, la resignificación estética de la fealdad, como señaló Umberto Eco, nos hace discurrir sobre la marginalidad de las minorías y sobre los monstruos que transitan en la vida cotidiana como un espectáculo que negamos, pero que al mismo tiempo nos define como sociedad (Eco, 2011: 418).

La segunda categoría que proponemos para analizar la ficción terrorífica es la transgresión cronotópica. Aquí el predominio del terror sobrenatural es innegable, pues los tópicos más recurrentes en esta distribución son las presencias fantasmales, la alteración del tiempo y el espacio, las distorsiones psíquicas de la realidad y las dimensiones paralelas (La casa en el confín de la tierra de William Hope Hodgson o La maldición de Hill House de Shirley Jackson). Según Patricia García, «la transgresión que se formula a través de la inversión de jerarquías espaciales desencadena una reflexión crucial: nuestra realidad puede ser igual de artificial que sus réplicas o incluso tan solo una réplica de otras realidades» (2016: 81$)$.

La tercera forma de entender el terror en la ficción es la transgresión de los paradigmas sociales; categoría que formalmente se aleja del efectismo fantástico pero que de igual manera plantea la eventualidad de lo imposible a través de la inexplicabilidad de la violencia, es decir, la imposibilidad de otorgar racionalidad a ciertos actos humanos inconcebibles. Esta categoría integra tópicos como la marginalidad del sujeto, la autodestrucción, el canibalismo y el horror sectario. Desde mi punto de vista, el eje articulador de este tipo de obras recae en la maldad, dando lugar a la retórica de la perversión y lo abyecto (El monje de M. G. Lewis o «La lotería» de Shirley Jackson). Por lo tanto, no sería incorrecto afirmar que en esta categoría prima el sadismo como principio estético.

\section{La retórica del miedo en tres autores chilenos: Francisco Coloane, Luis Alberto Heiremans y Braulio Arenas}

Desde la década de 1950, la narrativa chilena comenzó a experimentar un paulatino cambio en su sistema de representación; la generación de este periodo manifestó un profundo rechazo hacia los vestigios de la escuela criollista y abrazó un escepticismo tajante ante la realidad. Esta actitud llevó a los autores a configurar una suerte de enmascaramiento de los resortes cotidianos y a reflexionar sobre temas universales, disociados de lo estrictamente localista y de las preocupaciones sociales: «La Generación de 1950 es morbosa, crítica, inconformista y algo erótica» (La Nación: 24 de abril de 1959), sentenció Ricardo Latchman en 1959 ante el auge de estos nuevos escritores, promulgados principalmente por Enrique Lafourcade gracias a su labor como editor y antologador. Según Leonidas Morales:

El proyecto de los nuevos narradores, en Chile y América Latina, estuvo orientado, en sus líneas principales, por las prácticas creadoras, críticas y teóricas de los movimientos vanguardistas europeos de entre las dos guerras mundiales. Estas prácticas asumieron la condición urbana de lo moderno, sepultaron el tipo de obra artística de la tradición realista e instalaron otro, regido por un fragmentarismo descentrado, mientras simultáneamente se abrían a un doble horizonte utópico: estético (un nuevo arte) y político (una nueva sociedad) (Morales, 2008: 18). 


\section{Tropelías. Revista de Teoría de la Literatura y Literatura Comparada, 32 (2019) \\ Transgresiones de la realidad: aproximaciones al cuento de terror chileno moderno (1950-1960)}

Si bien el predominio del realismo fue evidente en el sistema literario de la segunda mitad del siglo XX, el interés por lo fantástico comenzó a aflorar de manera más o menos progresiva en la narrativa breve. El influjo determinante de las vanguardias europeas, el éxito del Boom y la instauración de la escuela neorrealista argentina dio lugar a una serie de propuestas inventivas disociadas del realismo. En palabras del crítico Ángel Rama:

[...] la cosmovisión fantástica fue sufriendo una suerte de nacionalización que concluyó situando la irrupción del estremecimiento fantástico, su repentina ruptura, en el seno de una realidad engañadora pero aparentemente acogedora. Fue primero mediante un tipo de aproximación simbólica, distorsionada y hasta grotesca, luego mediante una inserción cautelosa y por ende trágica del discurso de la vida cotidiana (Rama, 2008: 169).

En Chile, muchos autores experimentaron ocasionalmente con recursos estilísticos y temáticos próximos (o inmersos) en la arquitectura de lo fantástico, muchas veces alejados de las particularidades de su propio proyecto narrativo. De ahí en adelante es posible advertir una diacronía del cuento chileno de terror en sus dos vertientes: sobrenatural y sustancial. Sin embargo, es necesario precisar que a diferencia de otros autores canónicos latinoamericanos como Juan Rulfo, Julio Cortázar o Juan José Arreola, que exploraron lo sobrenatural en gran parte de su corpus literario, la producción de los narradores chilenos fue limitada y ocasional, dando a conocer sus aportaciones al género en antologías generacionales o en recopilaciones particulares, como Antología del Nuevo Cuento Chileno (Zig-Zag, 1954); Cuentos de la Generación del 50 (Editorial del Nuevo Extremo, 1959) y Antología del Cuento Chileno (Importadora Alfa Ltda., 1985), de Enrique Lafourcade; Antología del cuento chileno moderno (Editorial del Pacífico, 1965), de María Flora Yáñez; Cuentos de cabecera (Zig-Zag, 1967), de Hernán Poblete Varas y 28 cuentistas chilenos del siglo XX (Zig-Zag, 1963), de Luis Sánchez Latorre.

Entre los relatos en donde se manifiesta la transgresión del cuerpo, destaca «El témpano de Kanasaka», de Francisco Coloane (1910-2002), perteneciente al libro de cuentos Cabo de hornos (1941). El texto se basa en una leyenda de la zona austral de Chile que versa sobre la aparición fantasmal de un indio yagán atrapado en un témpano de hielo. El relato de Coloane retrata el periplo de unos tripulantes de Tierra del Fuego que deben atravesar las tempestuosas aguas del canal de Beagle, para llegar al presidio de Ushuaia en la localidad Yendegaia con un cargamento ilegal de licor. En su trayecto, se enfrentarán a la portentosa visión del Témpano de Kanasaka; una gran mole de hielo conducida por un espantoso cadáver, el cual, según el relato popular, conducía a los marineros a una muerte segura. Como en la mayoría de los relatos de Coloane, la presencia de una geografía portentosa establece el determinismo telúrico: principio en donde la naturaleza se configura como una entidad monstruosa y amenazante. Dicho tópico, lo podemos rastrear intertextualmente en obras de terror clásicas como El buque fantasma (1837-1839), de Frederick Marryat o en el ciclo de relatos marítimos de William Hope Hodgson.

Lo fantástico en el relato proviene de la dimensión inexplorada de la naturaleza, distanciándose del plano real. Los cuentos de Coloane son breves crónicas de la pugna entre el hombre y el ecosistema primitivo, el cual siempre termina revelando la insignificancia del ser humano: «La mole blanquecina 
se acercó: tenía la forma cuadrada de un pedestal de estatua y en la cumbre, ¡oh visión terrible!, un cadáver, un fantasma, un hombre vivo, no podría precisarlo, pues era algo inconcebible, levantaba un brazo señalando la lejanía tragada por la noche» (Coloane, 2014: 51). La visión monstruosa que emerge desde las profundidades del mar, responde a la categoría de la «magnificación» propuesta por Ana Casas (2012), ya que la formidable aparición excede los rasgos convencionales de los elementos naturales. Por otra parte, el reviniente aferrado al témpano simboliza la llegada inexorable de la muerte y, al mismo tiempo, la degradación de los pueblos originarios a causa de la invasión de los colonos europeos; conclusión que se infiere de las palabras finales del narrador una vez que ha llegado a tierra firme: «en mi recuerdo perduraba como un símbolo la figura hierática y siniestra del cadáver del yagán de Kanasaka, persiguiendo en el mar a los profanadores de esas soledades, a los blancos civilizados que han ido a turbar la paz de su raza y a degenerarla con el alcohol y sus calamidades. Y como diciéndoles con la mano estirada: “¡Fuera de aquí!”»(Coloane, 2014: 53).

La transgresión de los parámetros sociales, categoría que implica la vulneración física del sujeto a través del uso hiperbólico de la violencia y la personificación de la maldad, la podemos observar en otro relato de Coloane, «La voz del viento», recogido también en Cabo de Hornos. En el texto se narra la historia del gringo Denis, un cuidador de ganado en la isla de la Tierra del Fuego, que debe afrontar la soledad y las inclemencias del clima junto a su mujer, Lucrecia; una prostituta que decide seguir al protagonista para mejorar su vida. Sin embargo, Denis comienza a obsesionarse con la idea de degollar ovejas, añorando su antiguo trabajo como carneador en la estancia de China Creek. Lucrecia aborrece su nueva vida en la helada meseta y recrimina a su marido por los padecimientos que debe soportar en aquella zona extrema. La soledad se hace insoportable y una noche el gringo asesina a su esposa con su cuchillo predilecto. Luego de enterrar el cadáver experimenta una sensación de alivio, pero a los pocos días la culpa y el arrepentimiento se imponen.

De esta forma, la locura del personaje se impone en medio de un paisaje majestuoso que reclama su crimen a través de una insoportable voz que cuela en el viento: «La voz del viento era como un látigo enorme que lo azotaba, el zumbido le trepanaba las sienes, le aserraba los tímpanos, metiéndosele por dentro y barrenándolo» (Coloane, 2014: 53). La amenaza, aparentemente sobrenatural, deviene de la inestabilidad mental del protagonista, quien al final es consumido por la naturaleza; motivo literario presente también en los cuentos deterministas de Baldomero Lillo y en los relatos psicológicos de Poe. De esta forma, Coloane desplaza el principio civilizador al estado primitivo del sujeto, quebrantando las normas sociales y el orden institucional.

Otros ejemplos de la transgresión del cuerpo en la narrativa fantástica del periodo, son «El cuerpo restante» (1954) y «Miguelito» (1959), de Luis Alberto Heiremans (1928-1964); en el primero observamos el motivo del intercambio de cuerpos, el cual es propiciado por el desplazamiento incorpóreo del alma. Orión, un anciano mago, enseña el arte de la disgregación a Adelaida y Cecilia, sus compañeras de pensión en la calle Grajales, en el centro de Santiago. Juntos recorren las arterias urbanas por las noches para combatir el tedio cotidiano: «Era maravilloso. Solíamos regresar al amanecer y encontrábamos los cuerpos descansados, prontos a iniciar una nueva jornada. Esto duró un 
mes, más o menos. En un comienzo, partía a vagabundear en compañía de Orión; pero muy pronto me independicé e hice mi vida» (Heiremans, 2015: 255). Sin embargo, el terror se suscita cuando Adelaida regresa una mañana y se percata de que su cuerpo ha sido ocupado por el alma del hechicero, quien ha decidido intercambiar su avejentado organismo por el de la joven. El cuento pareciera ser una reversión del relato de H. G. Wells, «La historia del difunto míster Elvesham» (1896), en donde se presenta el mismo motivo, pero sujeto a la especulación científica. En ambos relatos se alegoriza el miedo a la vejez y las posibilidades fantásticas para aplacarla robando la juventud ajena. También encontramos rasgos de otros cuentos fantásticos hispanoamericanos que se vinculan intertextualmente con dicho motivo, como «Alma callejera» (1882), de Eduardo Wilde, en donde lo sobrenatural se focaliza en el hecho de que el alma es capaz de habitar otros espacios más allá del cuerpo, entendida como una cárcel que condiciona la libertad del espíritu, y el relato «Axolotl» (1952), de Julio Cortázar; contemporáneo a Heiremans y enmarcado también en los parámetros de lo neofantástico, en donde lo imposible recae en los mismos personajes y en las distorsiones de su propia concepción de lo real (la trasmutación cortazariana se produce cuando el narrador personaje se transforma en un pez que observa obsesivamente en un acuario), distanciándose de los agentes externos (vampiros, fantasmas, seres monstruosos, etc.) que suponían un quiebre con los paradigmas positivistas del siglo XIX.

En el caso de «El cuerpo restante», la cotidianidad monótona de la protagonista la llevan a explorar nuevos niveles de realidad que desarticulan la verosimilitud del texto. De esta forma, el abandono del cuerpo implica una aceptación y no una negación, ya que el hecho asombroso es entendido como una extensión más del mundo representado y no un quiebre absoluto. En este sentido, el terror sobrenatural recae en lo extratextual, pues trastoca los convencionalismos del lector.

Por otra parte, el cuento «Miguelito» nos presenta la historia de un hombre de 53 años, que luego de perder a su hermana Rosario, con la que vivió aislado casi toda su vida junto a su madre en una enorme casona, es atormentado por una gata que adopta como mascota. Aparte del animal, su única compañía es Carmela, la empleada doméstica que lo sigue tratando como un niño (de ahí el diminutivo «Miguelito»). La gata adquiere un tamaño desproporcionado y acecha constantemente al personaje, y frente a esta inusitada situación pide ayuda a su médico de cabecera, quien será el canalizador de los sucesos extraordinarios. Evidentemente, el nombre de la gata hace alusión a la automarginación del protagonista, estableciendo un nuevo plano de realidad en donde la casa opera como un espacio siniestro. La contraposición binaria entre el animal real y el animal fantástico se observa en el relato a través de la mutación que experimenta la mascota al convertirse en un ser amenazante que subvierte los parámetros de la domesticación, dando lugar al extrañamiento. En este punto, el calvario que vive el protagonista podría interpretarse como la incapacidad de asumir la soledad, sentimiento que se materializa en la gata:

—No sé cómo explicarle. Tendría que verla. Pero Carmela no deja que nadie se acerque a ella. Hay días en que a mí también me prohíbe entrar a la pieza donde está «Soledad». Pero eso no me importa. Lo único que quiero es que se la lleven. No puedo seguir viviendo ahí, doctor. Ayer, por ejemplo, me acerqué a acariciarla y la sentí crecer bajo mi mano, así, de golpe. Es horroroso. No puede imaginarse el miedo que me dio. Apoyar la mano sobre algo vivo que súbitamente cambia de forma, se agranda, se hace distinto... (Heiremans, 2017: 149-150). 
El animal cambia de forma y produce un miedo indecible en el personaje, quien tiene que lidiar no solo con el monstruo sino también con la confabulación de Carmela, quien protege al animal y lo aísla. En este sentido, podríamos afirmar que la gata es una transfiguración simbólica de la identidad del protagonista. También, otra lectura nos hace pensar que la «bestia» encarna el recuerdo nostálgico de la hermana de Miguelito, Rosario. Desde este punto de vista, el relato nos remite al clásico cuento de Cortázar, «Casa tomada» (1946) y al tema del incesto, el cual, al mismo tiempo, es retomado del relato La caída de la casa Usher (1839), de Poe, en donde lo fantástico enmascara las pulsiones sexuales de una pareja de hermanos empeñados en perpetuar los valores de una aristocracia degradada.

Por último, el final trágico del texto de Heiremans consolida la disolución de una unidad familiar represiva: Carmela y Miguelito son encontrados muertos en la casa, este último con los órganos intactos, pero con unas marcas de dientes en su cuello, sugiriendo este hecho el predominio del terror sobrenatural. No había señales de la gata, solo predominaba el silencio y el vacío. La sentencia final del narrador es crucial respecto a la tesis sobre la fabulación simbólica de la soledad: «Tal como había dicho Miguelito, la soledad era el único pecado. Él lo sabía y, sin embargo, la había dejado entrar. Ahora ya era demasiado tarde. Ambos habían sido devorados por la bestia» (Heiremans, 2017: 156).

Por otra parte, El cuento «En el tiempo», de Braulio Arenas (1913-1988), recogido por María Flora Yáñez para su Antología del cuento chileno moderno (1958), manifiesta una transgresión cronotópica fundada en la yuxtaposición de dos realidades. El relato presenta la historia de un aviador del ejército que es enviado a una misión de reconocimiento para develar los emplazamientos de la facción enemiga. Al realizar el despegue durante la madrugada se percata de que el motor de la avioneta falla, por lo que se ve obligado a realizar un aterrizaje forzoso. Sin embargo, nadie responde desde el centro de mando y la pista muta de forma extraordinaria, convirtiéndose ahora en un lugar completamente abandonado y roído, impidiendo su retorno. El choque entre lo posible y lo imposible sucede cuando el protagonista advierte la trasmutación de su realidad, situándolo en una dimensión sobrenatural:

Volvió a pasar por encima de la cancha. Pero esta, en contados segundos, había sufrido una metamorfosis diabólica, más perceptible ahora, pues las primeras luces del amanecer se insinuaban por entre las sombras. Se trataba de un campo sobre el cual hubiera llovido azufre y sal, donde ni el menor vestigio de algo viviente podía advertirse (Arenas, 1965: 42).

Esta anomalía ficcional es denominada por David Roas como «tiempo convergente», donde lo fantástico se manifiesta a partir de la confluencia de dos (o más) tiempos en un mismo instante. Es decir, se produce «la imposible comunicación entre dos estados temporales y, por tanto, entre dos órdenes de realidad» (Roas, 2012: 110). En términos intertextuales, este mismo motivo (aunque con otras variantes) lo observamos en otros cuentos fantásticos hispanoamericanos del periodo, como «Viaje a la semilla», de Alejo Carpentier, «El milagro secreto», de Jorge Luis Borges, «La noche boca arriba», de Julio Cortázar o «Una partida de ajedrez», del escritor chileno Miguel Arteche, donde un juego de mesa transporta a los personajes a dos planos temporales distantes entre sí. 
El miedo, como efecto estético, recae en el hecho inadmisible de un espectro que surca los cielos en una eternidad circular, desplazando la historia de base, sujeta a la hiperrealidad transgredida, al plano de la leyenda como una anécdota persistente en el imaginario popular, haciendo converger, de esta forma, dos tradiciones narrativas para configurar lo sobrenatural. Además, el léxico empleado por el narrador construye una red semántica macabra: «malignamente muda»; «metamorfosis diabólica»; «Cerro del Diablo», dan cuenta de esta condición. Además, el carácter fantasmal y errante que adquiere el aviador se legitima en la declaración final del narrador:

Son los mismos campesinos de la región los encargados de iluminar en parte esta historia. Ellos mantienen una leyenda, una leyenda transmitida de padres a hijos con conmovedora perseverancia, una leyenda que se cuchichean unos a otros en las noches invernales, una leyenda (pero solo se trata de una leyenda), una leyenda que asegura que hace doscientos cincuenta años atrás hubo, realmente, un aeródromo en ese sitio, y que, desde ese aeródromo, una madrugada partió un aviador en un pequeño avión de reconocimiento sin que nunca más pudiera volver a él y que ciertas noches es posible ver al aparato moviéndose loco por el cielo, como una pretérita hoja de calendario (Arenas, 1965: 42).

En conclusión, desde 1950, la narrativa chilena manifiesta profundos cambios en el sistema de representación. Los autores se distancian de la estela naturalista, universalizando los motivos literarios y adentrándose en la otredad fantástica para desarticular las superficies de la realidad. En este sentido, los asuntos imaginarios comienzan a proliferar en el formato del cuento. A pesar de que son pocos los autores que dedicaron gran parte de su producción a la fabulación macabra, muchas piezas literarias aparecieron en diversas antologías para dar cuenta de la sensibilidad postmoderna. La subversión de los sistemas aparentemente inmutables, junto con la diversidad de temas en torno a lo insólito, ratifican el desarrollo de lo terrorífico literario. En consecuencia, podemos entender el terror como una forma estética autónoma que atraviesa tanto lo fantástico como las representaciones realistas. Por lo tanto, es evidente la necesidad de atender el desarrollo de la literatura no mimética en Chile y sus diversas manifestaciones, en donde el terror, como pudimos constatar, ha tenido una clara presencia.

\section{Referencias bibliográficas}

Arenas, B. (1965): «En el tiempo», en M. F. YÁÑEZ, ed., Antología del cuento chileno moderno. Santiago, Editorial del Pacífico, pp.39-42.

BAUMAn, Z. (2015): Miedo líquido. Barcelona, Paidós.

BURKE, E. (2010): De lo sublime y de lo bello, Madrid, Alianza.

CARRERA GARRIDO, M. (2015): «El terror sí tiene forma: delimitación teórica de una categoría estética», en N. Álvarez y A. Abello, coords., Espejismos de la realidad. Percepciones de lo insólito en la literatura española (siglos XIX-XXI). León, Servicio de Publicaciones de la Universidad de León, pp. 75-84.

CASAS, A. (2012): Las mil caras del monstruo. Sevilla, Bracket cultura.

Colonne, F. (2014): Cabo de Hornos. $10^{\circ}$ ed. Santiago, Zig-Zag. 
Diamantino, J. (2017): «Fronteras de la alteridad. Lo fantástico y sus límites», en J. Diamantino, C. HeIREMANS y J. MiLlas, Rutas inciertas. Nuevos cuentos chilenos de terror, misterio y fantasía. Santiago de Chile, Cuarto Propio, pp. 15-25.

ECO, U. (2011): Historia de la fealdad. Barcelona, Random House Mondadori.

FREUD. S. (2013): «Lo siniestro», en S. Freud, Obras completas. Madrid, Siglo veintiuno editores, pp. 2083-2505.

GARCÍA, P. (2016): «Distorsiones espaciales: maqueta fantástica como transgresión entre continente y contenido», en N. Álvarez, A. Abello y S. FernándeZ, coords., Territorios de la imaginación. Poéticas ficcionales de lo insólito en España y México. León, Servicio de Publicaciones de la Universidad de León, pp. 73-82.

Heiremans, L. (2015): «El cuerpo restante», en J. Diamantino, C. Heiremans y V. Barros, eds., Cuentos chilenos de terror, misterio y fantasía. Santiago, Cuarto Propio, pp. 253-260.

(2017): «Miguelito», en J. Diamantino, C. Heiremans y J. Millas, eds., Rutas inciertas. Nuevos cuentos chilenos de terror, misterio y fantasía. Santiago, Cuarto Propio, pp. 141-160.

LigotTI, T. (2016): Noctuario. Relatos extraños y terroríficos. Madrid, Valdemar.

LOVECRAFT, H. P. (2008): Supernatural horror in literature, en H. P. LOVECRAFT, The complete fiction. New York, Barnes and Noble, pp. 1041-1098.

MANCILla, M. (2017): «Lo siniestro como motivo romántico», en V. SERRANO Y A. CASTILLA, eds., La filosofía, el terror y lo siniestro. Murcia, Plaza y Valdés, pp. 53-71.

MoRAlES, L. (2008): De muertos y sobrevivientes. Narración chilena moderna. Santiago, Cuarto Propio.

RAMA, Á. (2008): La novela en América Latina. Panoramas 1920-1980. Santiago de Chile, Ediciones Universidad Alberto Hurtado.

RoAs, D. (2011): Tras los límites de lo real. Una definición de lo fantástico. Madrid, Páginas de Espuma.

- (2012): «La perversión fantástica del tiempo», en F. GARCía y M. C. BATALHA, Vertientes teóricas e ficcionais do insólito. Río de Janeiro, Editora Caetés, pp. 106-113. 